DOI: http://dx.doi.org/10.12957/demetra.2014.10460

\title{
Avaliação qualitativa de cardápios em uma unidade de alimentação e nutrição localizada em Vitória-ES
}

\section{Qualitative evaluation of menus in food service located in the city of Vitoria-ES}

Jackline Freitas Brilhante de São Josél

1 Departamento de Educação Integrada em Saúde, Universidade Federal do Espírito Santo. Vitória-ES, Brasil.

Correspondência / Correspondence Jackline Freitas Brilhante de São José E-mail: jackline.jose@ufes.br

\section{Resumo}

Objetivo: Avaliar a qualidade do cardápio em uma Unidade de Alimentação e Nutrição localizada no município de VitóriaES. Métodos: Aplicou-se o método de avaliação qualitativa das preparações de cardápios (AQPC) oferecidos em 51 dias. Resultados: Ao realizar a análise do cardápio, verificou-se a presença de frutas e folhosos em 96,08\% dos dias avaliados. As preparações servidas indicaram monotonia de cores, apresentando 50,98\% de cores iguais. Das carnes gordurosas mais frequentes no cardápio, destacam-se linguiças toscana, pernil e hambúrguer. Em 70,58 \% dos dias avaliados, o cardápio apresentou mais de um alimento rico em substâncias causadoras de flatulência. Em 23,53\% dos dias avaliados, foram aplicadas as mesmas técnicas de cocção para os pratos proteicos, sendo que preparações cozidas e frituras foram as mais empregadas. Os doces estiveram presentes em $88,23 \%$ dos dias avaliados, sendo que em $50,98 \%$ dos dias o cardápio apresentava frituras associadas aos doces dentre as preparações oferecidas. A conserva, quando presente, foi utilizada em pequenas quantidades em preparações servidas como guarnição. Conclusões: Os resultados da avaliação do cardápio indicam alta oferta de frutas e hortaliças na UAN. Entretanto, a alta oferta de alimentos ricos em enxofre, carnes gordurosas, doces, frituras e monotonia de cores indica a necessidade de ajuste dos cardápios, para melhorar os aspectos nutricionais e sensoriais das preparações oferecidas aos clientes.

Palavras-chave: Planejamento de Cardápio. Serviços de Alimentação. Qualidade dos Alimentos. 


\section{Abstract}

Objective: This study aimed to evaluate the quality of the menu in a Food Service located in the city of Vitoria-ES. Methods: The method of qualitative assessment of menu preparations (AQPC) was applied to evaluate preparations offered in 51 days. Results: In performing the menu analysis, we verified the presence of leafy vegetables and fruits in $96.08 \%$ of the days measured. The preparations served indicated monotony of color, showing $50.98 \%$ of same colors. Fatty meats were usually present in menus, such as Tuscan sausages, ham and hamburger. In $70.58 \%$ of the days assessed, the menu had more than one food rich in substances that cause flatulence. In $23.53 \%$ of the days, were applied the same cooking techniques for protein food, and cooked and fried preparations were habthe most common. Sweets were present in $88.23 \%$ of the days assessed, and in $50.98 \%$ of days menus featured fried associated with sweets among the preparations offered. Canned vegetables were used in small amounts in preparations served as a garnish. Conclusions: The results of menu evaluation indicate high supply of fruits and vegetables in the food service. However, the high supply of sulfur-rich foods, fatty meats, sweets, fried foods and monotony of color indicate the need to adjust the menus to improve the nutritional and sensory preparations offered to customers.

Keywords: Menu Planning. Food Services. Food Quality.

\section{Introdução}

A realização de refeições fora do lar tornou-se um hábito que favoreceu a ampliação do setor de serviços de alimentação. ${ }^{1-3}$ Segundo a Associação Brasileira de Refeições Coletivas (ABERC), o mercado de refeições coletivas fornece 11,7 milhões de refeições/ dia, movimenta uma cifra de 16,6 bilhões de reais por ano, oferece 195 mil empregos diretos e representa para os governos uma receita de um bilhão de reais anuais entre impostos e contribuições. ${ }^{4}$

O mercado da alimentação é desmembrado em alimentação comercial e alimentação coletiva, sendo que o estabelecimento que trabalha com produção e distribuição de alimentos para coletividades recebe o nome de Unidade de Alimentação e Nutrição (UAN). Este é um conjunto de áreas com o objetivo de operacionalizar o fornecimento 
de nutrientes para coletividades. As UANs podem ser estabelecidas em complexos industriais, empresas ou escolas, sob diversas formas de gerenciamento. ${ }^{5}$

As UANs têm como finalidade produzir refeições segundo padrões higiênicosanitários adequados, proporcionar refeições nutricionalmente balanceadas quanto ao conteúdo de nutrientes, colaborar para manutenção ou recuperação da saúde e auxiliar no desenvolvimento de hábitos alimentares mais saudáveis. ${ }^{5}$

Para elaboração dos cardápios, deve-se garantir a oferta de todos os nutrientes imprescindíveis para uma vida saudável, moderação, ofertando-se todos os alimentos, porém alguns em baixa quantidade, devido à composição, e proporcionalidade, onde se deve observar a proporção, conforme os grupos a que pertencem. ${ }^{6}$

O planejamento dos cardápios da unidade deve ser realizado por nutricionista habilitado, tendo como a finalidade programar refeições que atendam aos requisitos como hábitos alimentares dos clientes, qualidade higiênico-sanitária, adequação ao mercado de abastecimento e à capacidade de produção. ${ }^{6,7}$

Dentre os métodos utilizados para avaliação de cardápios, o método de Avaliação Qualitativa das Preparações de Cardápios (AQPC) tem sido recomendado. ${ }^{8}$ Este visa auxiliar o profissional na elaboração de um cardápio mais adequado do ponto de vista nutricional e de alguns aspectos sensoriais dentro dos parâmetros de saúde cientificamente preconizados. ${ }^{9} \mathrm{OAQPC}$ é um método que tem como finalidade a avaliação de cores, técnicas de preparo, repetições, combinações, oferta de folhosos, frutas, tipo de carnes e teor de enxofre dos alimentos. ${ }^{7,8}$ É feita a análise do cardápio diário, que implica avaliação mensal, reunindo dados semanais tabulados em relação ao número total de diais averiguados.

As refeições oferecidas aos clientes são planejadas de forma a permitir a adequação da distribuição dos nutrientes. Deste modo, é importante que haja avaliação periódica dos cardápios, no intuito de promover hábitos mais saudáveis. Nesse contexto, o objetivo do presente estudo foi avaliar a qualidade das preparações do cardápio de uma UAN localizada na cidade de Vitória-ES, Brasil.

\section{Material e Métodos}

Foi realizado, no período de julho a setembro de 2013, estudo de caso do tipo descritivo, numa Unidade de Alimentação e Nutrição (UAN) localizada na cidade de Vitória, estado do Espírito Santo. A UAN estudada distribui 500 refeições por dia, somente para almoço, cinco dias na semana. 
Trata-se de uma UAN institucional, na qual a empresa trabalha em modalidade de comodato, sendo que as refeições são produzidas em outra UAN e transportadas até o local de distribuição. A unidade possui cardápio padrão médio, composto por prato principal e opção, acompanhamento (arroz branco ou arroz integral e feijão simples), quatro tipos de saladas, guarnição, dois tipos de sobremesas (doce e fruta) e o refresco. Trata-se de um sistema de distribuição misto, no qual apenas as saladas são servidas pelos próprios clientes e as demais preparações são servidas pelos funcionários a partir de um porcionamento pré-definido, dispondo os alimentos em bandejas estampadas na presença do cliente.

A Avaliação Qualitativa das Preparações do Cardápio (AQPG) foi realizada segundo o método proposto por Veiros ${ }^{7}$ e Proença, ${ }^{8}$ sendo analisados os cardápios oferecidos no almoço, totalizando 51 dias de estudo. Avaliaram-se técnicas de cocção, aparecimento de frituras isoladas e associadas aos dias com oferta de doces, a cor das preparações e os alimentos empregados no cardápio, presença de alimentos ricos em enxofre (sendo observado também o fornecimento de alimentos ricos em rafinose), o aparecimento de frutas e folhosos e a presença de carne gordurosa nos dias em que não há preparo de fritura, assim como repetições de pratos principais.

Para realizar a análise das preparações ricas em enxofre, foram considerados e contabilizados como alimentos flatulentos sulfurados: abacate, acelga, aipo, alho, amendoim, batata-doce, brócolis, castanha, cebola, couve-de-bruxelas, couve-flor, ervilha, gengibre, goiaba, jaca, lentilha, maçã, melancia, melão, milho, mostarda, nabo, nozes, ovo, rabanete, repolho e uva. ${ }^{9}$ Os cardápios que ofereceram dois ou mais dos alimentos citados anteriormente foram considerados com alto teor de enxofre. O feijão, presente diariamente nas refeições, não foi considerado nesta análise.

Quanto à cor, os cardápios foram considerados monótonos quando apresentavam preparações com cores similares no mesmo dia como, por exemplo, salada de cenoura, batata baroa, mamão como sobremesa e suco de manga, com exceção das carnes e do feijão.

Consideraram-se como carnes gordurosas aquelas em que o teor de gordura ultrapassava $50,0 \%$ do valor energético total ${ }^{9}$. Foram contabilizadas nos dias avaliados, a oferta de frutas, doces, frituras, folhosos, doces associados a frituras, conservas, e repetição da técnica de preparo dos pratos proteicos. ${ }^{7,9}$

A unidade estudada foi previamente contatada e o responsável técnico autorizou a realização do trabalho. A avaliação do cardápio foi realizada a partir da observação do percentual de ocorrência diária dos alimentos ou preparações relativo a cada critério. Em seguida, foi contabilizado, por semana e por mês, o número de dias em que houve a ocorrência de cada critério analisado e, por fim, calculou-se a porcentagem, considerando 
todos os dias do estudo. Todos os dados foram tabulados e analisados no programa Microsoft Excel® 2010.

\section{Resultados}

Os resultados da aplicação do método AQPC nos cardápios da UAN deste estudo encontram-se na tabela 1.

A avaliação qualitativa dos cardápios indica a presença de frutas e folhosos na maioria dos dias avaliados. O cardápio da UAN apresenta elevado teor calórico, pois verificouse alto percentual de presença de preparações que utilizam como técnica de preparo a imersão em óleo (frituras), carnes gordurosas como matéria-prima para a elaboração dos pratos principais e opções e de doces como opção de sobremesa.

A monotonia de cores foi observada, sendo prevalentes as cores amarela e laranja nas preparações oferecidas, como por exemplo, servir quibebe de abóbora como guarnição, cenoura na salada, mamão como sobremesa e refresco de manga.

Ressalta-se que em alguns dias houve associação de alimentos ricos em enxofre com outros ricos em rafinose, como grão-de-bico, que geralmente foi servido como salada. A associação de alimentos ricos em enxofre e aqueles que possuem grande quantidade de rafinose podem dificultar o processo digestivo. ${ }^{9}$

Dentre as carnes gordurosas mais frequentes no cardápio, destacam-se linguiças toscana, pernil e hambúrguer. Destaca-se ainda a presença frequente das preparações "estrogonofe de carne bovina e carne de frango", oferecidas em um mesmo mês cinco e 11 vezes no cardápio, respectivamente. Vale ressaltar que essa preparação tem como um dos seus ingredientes o creme de leite, cuja utilização implica aumento do valor calórico e lipídico desta preparação.

Quanto ao tipo de sobremesa, na maioria dos dias estudados, a UAN disponibilizava diariamente em seu cardápio fruta como, por exemplo, uma maçã pequena e doce, como por exemplo, uma colher de sopa de doce de leite industrializado, sendo que o comensal fazia a escolha de acordo com sua preferência. Observou-se que nos dias de avaliação, houve preferência pelos comensais pela fruta como sobremesa.

Em nenhum dos dias avaliados foi verificada a presença de conservas servidas como saladas. Quando presente, a conserva foi utilizada em pequenas quantidades como ingrediente de preparações servidas como guarnição. Farofa $(23,52 \%)$, polenta $(19,60 \%)$ e macarrão $(13,72 \%)$ foram as preparações de guarnição que apresentaram maior percentual de ocorrência no cardápio da unidade. 
Em 23,53\% dos dias avaliados, foram aplicadas as mesmas técnicas de cocção para os pratos proteicos. Dentre as técnicas dietéticas de preparo mais empregadas, observou-se preferência por preparações cozidas $(70,58 \%)$ e frituras $(50,98 \%)$.

Tabela 1. Análise dos cardápios fornecidos em uma UAN localizada em Vitória-ES, 2013.

\begin{tabular}{cccccccccc}
\hline Meses & $\begin{array}{c}\text { Dias } \\
\text { de Cardápio }\end{array}$ & Frutas & Folhosos & $\begin{array}{c}\text { Cores } \\
\text { iguais }\end{array}$ & $\begin{array}{c}\text { Ricos em } \\
\text { enxofre }\end{array}$ & $\begin{array}{c}\text { Carnes } \\
\text { gordurosas }\end{array}$ & Frituras & $\begin{array}{c}\text { Doce } \\
\text { + Frituras }\end{array}$ \\
\hline Julho & 18 & 16 & 17 & 7 & 12 & 13 & 10 & 15 & 10 \\
Agosto & 24 & 24 & 23 & 13 & 19 & 16 & 11 & 22 & 11 \\
Setembro & 9 & 9 & 9 & 6 & 5 & 7 & 5 & 8 & 5 \\
$\begin{array}{c}\text { Total em dias } \\
\text { \% de }\end{array}$ & 51 & 49 & 49 & 26 & 36 & 36 & 26 & 45 & 26 \\
ocorrência & 100 & 96,08 & 96,08 & 50,98 & 70,58 & 70,58 & 50,98 & 88,23 & 50,98 \\
\hline
\end{tabular}

\section{Discussão}

O cardápio é o ponto de partida para o planejamento de compras, satisfação dos clientes e composição dos custos na UAN. Segundo Ornellas, ${ }^{10}$ um bom cardápio deve apresentar os princípios de variedade e harmonia. Com a variedade de alimentos, garante-se a diversificação de sabores, consistência, temperatura e cores. A harmonia contribui para a associação adequada de cores, consistência e de sabores, o que exige sentido estético e artístico. Ademais, a fim de atender aos objetivos da UAN, deve-se considerar a adequação nutricional do cardápio oferecido, o que por sua vez torna desafiador o trabalho do nutricionista. ${ }^{11}$

Os altos percentuais de presença de folhosos e frutas no cardápio da UAN em estudo indicam a preocupação da unidade em fornecer alimentos fonte de vitaminas, minerais e fibras. Sabe-se que quando consumidos, esses alimentos podem ajudar a reduzir o risco de doenças crônicas não transmissíveis (DCNT). ${ }^{12}$ 
Segundo a Organização Mundial da Saúde, é recomendado o consumo de $400 \mathrm{~g}$ de frutas e hortaliças diariamente. ${ }^{13} \mathrm{~A}$ variedade de cores dos alimentos fornecidos no cardápio é fator crucial no planejamento de refeições, pois isto favorece o fornecimento variado de nutrientes ao cliente da UAN. Além disso, desperta o interesse deste, devido à presença de cores vibrantes e contrastantes, visto que o primeiro contato cliente-alimento é visual. Dessa forma, as preparações com cores variadas propiciam maior aceitação pelo consumidor. ${ }^{6,8}$ Dos dias avaliados, $50,98 \%$ apresentaram monotonia de cores entre as preparações do cardápio, que podem estar associadas a desajustes no planejamento do cardápio ou a modificações realizadas no dia da execução das preparações, devido à ausência de certos gêneros alimentícios.

Deve-se destacar a presença de frituras no cardápio da UAN nos dias avaliados. Como esta técnica de preparo é rápida, geralmente ela é escolhida para dinamizar o preparo de alguns alimentos. A baixa oferta de preparações que utilizam esta técnica de cocção é considerada positiva para a promoção da saúde, pois é sabido que o alto consumo de lipídios é fator de risco para doenças cardiovasculares. ${ }^{14}$

Outro critério analisado pelo método AQPC foi a oferta de carnes gordurosas que estavam presentes no cardápio. Em estudos realizados em UANs institucionais, Ramos et al. ${ }^{11}$ e Passos ${ }^{15}$ encontraram percentual inferior a este item avaliado, sendo estes iguais a $52,4 \%$ e $37,5 \%$, respectivamente. Destaca-se que as carnes gordurosas coincidiram com a oferta de preparações fritas e doces em 19,60\% dos dias analisados, fato que colaborou para o aumento do valor calórico do cardápio. Deve-se buscar no planejamento dos cardápios que, no dia em que planejar servir carne mais gordurosa, atentar para o restante das preparações do dia, evitando oferecer, na mesma refeição, alimentos gordurosos, frituras e doces como sobremesa.

Na UAN estudada, em 70,58\% dos dias avaliados, o feijão estava associado a dois ou mais alimentos ricos em enxofre. Alimentos ricos em enxofre podem causar desconforto gástrico, devido ao elevado teor de compostos sulfurados. Além disso, a associação destes alimentos com outros ricos em rafinose dificulta o processo digestivo. ${ }^{9} \mathrm{~A}$ rafinose é um oligossacarídeo encontrado em leguminosas como soja e feijão, que não é hidrolisada pelas enzimas humanas. ${ }^{7}$

As conservas eram utilizadas em pequenas quantidades em guarnições e pratos proteicos, com o objetivo de decorar ou finalizar algumas preparações. Deste modo, observa-se que nesta unidade havia o controle na utilização de conservas. Este ponto foi considerado positivo, pois esses alimentos apresentam grande quantidade de sódio em sua composição e há registros da relação entre o consumo excessivo de sal e desenvolvimento de doenças crônicas, como hipertensão arterial e câncer gástrico. ${ }^{16}$ 
A UAN disponibilizava, no balcão de saladas, molhos industrializados e sachês de sal, que eram utilizados de acordo com o interesse dos clientes. Deve ser atentar para este fato, pois esses produtos possuem grande quantidade de sódio. Deste modo, a UAN pode estar estimulando que clientes possuam hábitos alimentares inadequados.

A presença de doces, frituras e carnes gordurosas coincide com os hábitos alimentares de indivíduos obesos. A obesidade pode ocasionar patologias como diabetes tipo 2, hipertensão, dislipidemia e síndrome metabólica. ${ }^{17}$ As UANs são estabelecimentos promotores da saúde; assim, devem oferecer preparações nutricionalmente equilibradas e de acordo com os requisitos de qualidade sensorial exigido pelos clientes. ${ }^{18}$

Os resultados obtidos pela aplicação do método AQPC sugerem a necessidade de melhorias no planejamento dos cardápios, no sentido de reduzir o fornecimento de carnes gordurosas, frituras, doces e alimentos ricos em enxofre. A alimentação equilibrada é essencial para garantir a saúde e a capacitação do indivíduo, contribuindo para o aumento da produtividade e reduzindo os riscos de acidentes de trabalho.

Os problemas registrados no cardápio podem estar relacionados a dificuldades operacionais, como poucos equipamentos disponíveis para o preparo e falhas no prazo de entrega dos gêneros alimentícios.

\section{Conclusões}

Os resultados da avaliação do cardápio indicam alta oferta de frutas e hortaliças diariamente na UAN, o que é considerado um ponto positivo. Entretanto, a alta oferta de alimentos ricos em enxofre, carnes gordurosas, doces, frituras e a monotonia de cores indicam a necessidade de ajuste dos cardápios, para melhorar os aspectos nutricionais e sensoriais das preparações oferecidas aos clientes. Dentre as melhorias sugeridas, destaca-se a redução da oferta de carnes gordurosas, frituras, doces e conservas, e evitar a monotonia de cores e técnicas de cocção das preparações.

Assim, a utilização do método AQPG é uma ferramenta útil na elaboração de cardápios e permite detectar falhas e definir soluções a serem implementadas na revisão e adequação dos cardápios, de forma a considerar as exigências nutricionais que garantam a manutenção da saúde dos indivíduos e a satisfatória oferta de nutrientes. Além do AQPC, sugere-se a utilização de outros métodos de avaliação, como a pesquisa de satisfação, no intuito de obter informações relevantes que possibilitem a melhoria no serviço oferecido.

Ressalta-se a importância da realização de mais estudos que promovam a discussão sobre o tema. 


\section{Referências}

1. Alves MG, Ueno M. Restaurantes self-service: segurança e qualidade sanitária dos alimentos servidos. Rev. Nutr. 2010; 23(4):573-580.

2. Ungku-Fatimah UZA, Boo HC, Sambasivan M, Salleh R. Foodservice hygiene factors - the consumer perspective. Int J Hosp Manag. 2011; 30(1):38-45.

3. Gormley FJ, Rawal N, Little CL. Choose your menu wisely: cuisine-associated food-poisoning risks in restaurants in England and Wales. Epidemiol. Infect. 2011; 140(6):1-11.

4. Associação Brasileira das Empresas de Refeições Coletivas. História, objetivos e mercado [Internet]. 2013. [acesso set. 2013]. Disponível em: http://www.aberc.com.br/conteudo.asp?IDMenu=18

5. Abreu ES, Spinelli MGN. A unidade de alimentação e nutrição. In: Abreu ES, Spinelli MGN, Zanardi AMP. Gestão de unidades de alimentação e nutrição: um modo de fazer. 3. ed. São Paulo: Metha; 2009. p. 33-40.

6. Teichmann ITM. Cardápios: técnicas e criatividade. 7. ed. Caxias do Sul: EDUCS; 2009. 151p.

7. Veiros MB. Análise das condições de trabalho do nutricionista na atuação como promotor de saúde em uma unidade de alimentação e nutrição: um estudo de caso [dissertação]. Florianópolis: Universidade Federal de Santa Catarina; 2002.

8. Veiros MB, Proença RPCP. Avaliação qualitativa das preparações do cardápio em uma unidade de alimentação e nutrição - método AQPC, 2003. Nutr. Pauta 2003; 11(1):36-42.

9. Proença RPC, Sousa AA, Veiros MB, Hering B. Qualidade nutricional e sensorial na produção de refeições. 3 ed. Florianópolis: Editora UFSC; 2008. 221 p.

10. Ornellas LH. Técnica dietética: seleção e preparo dos alimentos. 8 ed. São Paulo: Atheneu; 2006.

11. Ramos AS, Souza FFR, Fernandes GCB, Xavier SKP. Avaliação qualitativa do cardápio e pesquisa de satisfação em uma unidade de alimentação e nutrição. Alimentos e Nutrição 2013; 24(1):1-7.

12. Philippi ST. Pirâmide dos alimentos: fundamentos básicos da nutrição. Barueri, SP: Manole; 2008. 383 p.

13. Organização Mundial de Saúde. Diet, nutrition and prevention of chronic diseases. Geneva: OMS; 2003

14. Lima FEL, Menezes TN, Tavares MP, Szarfarc SC, Fisberg RM. Ácidos graxos e doenças cardiovasculares: uma revisão. Rev. Nutr. 2000; 13(2):73-80.

15. Passos ALA. Análise do cardápio de uma unidade de alimentação e nutrição institucional em BrasíliaDF segundo o método "avaliação qualitativa das preparações do cardápio [monografia]: Brasília: Universidade de Brasília; 2008.

16. World Health Organization. Forum on reducing salt intake in populations. Reducing salt intake in populations: report of a WHO forum and technical meeting; 5-7 Oct. 2006, Paris, France. Geneva: WHO; 2006. 
17. Menegazzo M, Fracalossi K, Fernandes AC, Medeiros NI. Avaliação qualitativa das preparações do cardápio de centros de educação infantil. Rev. Nutr. 2011; 24(2):243-251.

18. Gelbcke G, Fernandes, AC, Carball TSL. Desenvolvimento de sobremesas diet e light e sua inclusão no cardápio de uma unidade de alimentação e nutrição. Demetra: Nutrição e Saúde 2012; 7(1):3-12.

Recebido: $12 / 4 / 2014$

Revisado: $15 / 9 / 2014$

Aprovado: 09/10/2014 